\title{
TRANSFORMACIONES DEL DERECHO PENAL COMO CONSECUENCIA DEL CAMBIO SOCIAL**
}

\section{Transformations in criminal law as a result of social change}

Wolfgang Frisch ${ }^{* *}$

Resumen: Este trabajo indaga en las transformaciones verificadas en Alemania en el ámbito de las sanciones penales y de los delitos en particular, así como en la dimensión procesal. Asimismo, advierte sobre el creciente fenómeno de "policialización" en la etapa previa al juicio y en los métodos de investigación, se pronuncia acerca del fortalecimiento de los derechos de la víctima y los cambios en el derecho probatorio, como por ejemplo, la relajación de las reglas sobre prohibición probatoria en el ámbito de la delincuencia grave. Finalmente se refiere a las nuevas formas de dar término al procedimiento penal, especialmente los acuerdos penales, por la complejidad que ha adquirido la investigación de ciertos delitos.

Palabras clave: Cambio social y evolución del derecho penal - transformación de los delitos y sanciones penales - "policialización" de la etapa previa al juicio y en los métodos de investigación - derecho probatorio - derechos de las víctimas - nuevas formas de término del proceso penal.

Abstract: This paper studies the changes implemented in Germany in the field of criminal penalties and some offenses, as well as the procedural dimension. It warns about the growing phenomenon of "policialización" ("policialization") in the pre-trial and investigation methods. It also refers to the tendency to strengthen the rights of the victim and the changes in the law of evidence, such as the relaxation of the ban on evidentiary rules in the field of serious crime. Finally it refers to new forms of closing criminal proceedings, especially criminal agreements (plea bargaining), due to the complexity that the investigation of certain crimes has acquired.

Keywords: Social changes and evolution of criminal law - changes in the field of criminal penalties and some offenses - "policialization" in the pre-trial and investigation methods - evidentiary rules - rights of the victim - new forms of closing criminal proceedings.

\footnotetext{
* Artículo que se funda en una ponencia presentada el día martes 26 de octubre de 2010, en la Facultad de Derecho de la Universidad Alberto Hurtado; traducción del Profesor de Derecho Penal en la Universidad Alberto Hurtado y de Los Andes, Dr. Gonzalo García Palominos (LL.M., Freiburg i.B.)

** Profesor Dr. Dr.h.c. Institut für Strafrecht und Strafprozessrecht Albert Ludwigs, Universität Freiburg. Correo electrónico: wolfgang.frisch@jura.uni-freiburg.de
}

Este artículo fue recibido el 28 de julio de 2014, siendo aprobada su publicación el 18 de diciembre de 2014. 
De los "tres pilares del derecho" -el derecho civil, el derecho penal y el derecho público- pareciera que el derecho penal es, a primera vista, el menos susceptible a las transformaciones sociales. Un determinado ámbito nuclear (como en los delitos de homicidio, lesiones, privación ilegítima de libertad, hurtos y robos) es aparentemente resistente a los cambios sociales y tiene una existencia permanente a lo largo del tiempo. Además, si bien es cierto que otros delitos se encuentran fuertemente relacionados con un determinado estado de la sociedad, sin embargo, estos se caracterizan a menudo por el hecho de presuponer órdenes de conductas prepenales (civiles, económicos o administrativos). ${ }^{1}$ El derecho penal se limita aquí a penalizar las desviaciones más graves a dichos órdenes de conducta. Con ello, los cambios sociales en el ámbito de tales delitos pueden reclamar, en mayor o menor medida, cambios importantes en el ámbito de los propios órdenes de conductas prepenales. A pesar de lo anterior, estos cambios no parecen provocarle grandes problemas al derecho penal. Evidentemente, este puede limitarse a establecer cuál de las nuevas normas necesitan de una salvaguardia penal comparable a las normas hasta ahora blindadas penalmente.

Sin embargo, las apariencias engañan. En realidad, el derecho penal también está sujeto en gran medida a las transformaciones sociales. Para ver esto, solo se requiere dirigir la mirada hacia las sanciones penales $\mathrm{y}$, en particular, concentrarse en la configuración de dichas sanciones. Pero, incluso, dentro del ámbito de los distintos delitos, en un análisis algo más detallado, se hacen evidentes los numerosos cambios en el derecho penal como consecuencia de la transformación de la sociedad. No menos sujeto a dichos cambios sociales se encuentra el proceso penal, al menos, en determinados ámbitos.

Para determinar tales conexiones se puede proceder de distintas maneras. Se puede considerar el derecho penal y sus transformaciones y plantear la pregunta si y en qué medida estas tienen su causa en las transformaciones de la sociedad. Naturalmente también se puede, en sentido opuesto, tener como punto de partida las transformaciones sociales y desde ahí ver en qué medida estas han dado lugar a cambios en el derecho (penal). El primer modo de proceder tiene la ventaja de que las modificaciones legales no solo no son ubicadas precipitadamente en la cuenta de un determinado cambio en el ámbito social, sino que además permite que se hagan visibles trasfondos multifactoriales. De ahí que aquella se tome como fundamento de lo que se expone a continuación.

Conceptualmente el término "transformación del derecho" es suficientemente claro para cada jurista y no requiere de ulterior explicación. Algo distinto sucede con el concepto "transformación de la sociedad", principalmente a causa de los distintos conceptos de sociedad. Entiendo el concepto en un sentido amplio: es decir, como una unidad de vida común entre seres humanos que está

\footnotetext{
${ }^{1}$ En este sentido, estos delitos son accesorios. Acerca de la accesoriedad del derecho penal así como de amplios ámbitos del derecho penal, FRISCH, (1993), pp. 5 y ss., pp. 9 ss.
} 
marcada por ciertos factores (no personales), como el idioma, las costumbres, criterios jurídicos, representación de valores. Pero también por condiciones materiales como los modos de producción, el sistema económico, el transporte u objetivos, como la movilidad, apertura o la cohesión de la sociedad, etc. ${ }^{2} \mathrm{La}$ transformación de la sociedad es, por consiguiente, un cambio en el ámbito de estos $\mathrm{u}$ otros factores que acuñan la sociedad y su estado. Cuando se toma conciencia de algunos cambios en el derecho penal (inclusive del derecho procesal), se hace evidente que las transformaciones sociales constituyen un factor explicativo esencial de las modificaciones del derecho penal.

\section{Transformación en el ámbito de las sanciones}

Probablemente sean las sanciones penales el ámbito general del derecho penal material que de manera más intensa haya sido modificado. Para esto no se necesita retroceder a la edad media o a comienzos de los tiempos modernos y analizar sus castigos crueles y degradantes e, incluso, sus mutilaciones. Solo basta con mirar a la época de entrada en vigor del actual Código Penal alemán (StGB) para que queden al descubierto las importantes modificaciones en el derecho penal alemán.

\section{Panorámica sobre los principales cambios}

Los cambios en el derecho penal no solo se refieren a la forma de reaccionar frente a un delito sino también a la medida y al monto con que las sanciones penales son aplicadas. Asimismo, se ha modificado notoriamente la relación mediante la cual se han aplicado y se aplican las sanciones penales.

a) En principio, en lo que concierne a las formas de sanción, el Código Penal alemán de 1871 conoció cuatro tipos diferentes de penas privativas de libertad y, adicionalmente, para delitos menores, la pena de multa. Constituían tipos de penas privativas de libertad la pena de reclusión (Zuchthausstrafe), prisión (Gefängnisstrafe), el internamiento (Einschließung) y la detención o arresto (die Haft). ${ }^{3}$ De esos cuatro tipos de penas privativas de libertad no queda prácticamente nada; estas fueron reemplazadas por una única pena privativa de libertad. ${ }^{4}$

\footnotetext{
2 Véase sobre el concepto de Sociedad y los factores que la acuñan: AMBROS (1965), pp. 427 y ss.; GANSLANDT (2005), pp. 756 y s.; HALDER/MÜLLER (2008), p. 122 s.; KAUPP (1974), pp. 460 y ss.; REHBINDER (2007), Nm. 31 ss., pp. 35 s.

3 Cfr. desde el antiguo derecho penal alemán el $\int 14$ y el $\int 15$ StGB para la reclusión (Zuchthausstrafe), el $\int 16$ para la prisión (Gefängnisstrafe), el $\int 17$ para la llamada fortaleza (Festungshaft) o internamiento (Einschließung) y el $\int 18$ para la detención (Haft).

${ }^{4}$ Sobre el trasfondo de la sustitución, véase primer informe escrito de la comisión especial para la reforma del derecho penal, BT-Drucks. V/4094, p. 8.
} 
Así como determinadas sanciones del Código Penal de 1871 han sido suprimidas en la actualidad, también existen algunas sanciones que eran desconocidas para el Código Penal de 1871 y que han sido introducidas al Código Penal actual. En especial, fueron incorporadas las así llamadas medidas preventivas para la lucha contra el delito (Verbrechensbekämpfung). Estas fueron introducidas al Código Penal el año 1933 como "medidas de seguridad y corrección", 5 fueron mantenidas después de la segunda guerra mundial y también luego de la reforma al derecho penal e, incluso, en los últimos años, han sido objeto de un importante fortalecimiento (en especial, en el ámbito del internamiento de seguridad). ${ }^{6}$ En general, el campo de las sanciones penales -en los últimos cien años y solo en lo relativo a los tipos de las sanciones- ha estado sujeto a drásticas modificaciones.

b) El nivel de la sanción penal y la relación entre penas privativas de libertad y penas pecuniarias constituye otro de los aspectos que han sufrido cambios importantes. Desde la entrada en vigor del Código Penal el monto o cuantía de las penas privativas de libertad ha disminuido, en la mayoría de los ámbitos, en forma constante y, en parte, significativamente. ${ }^{7} \mathrm{Al}$ mismo tiempo, las penas privativas de libertad ejecutadas (vollstreckte Freiheitsstrafe), que originalmente constituyeron la sanción central del derecho penal, se han convertido entretanto estadísticamente en un fenómeno marginal. Después de todo, la mayoría de las veces en que se impone una pena privativa de libertad esta es suspendida: algo así como el $70 \%$ de las penas privativas de libertad impuestas son modificadas por la remisión condicional. ${ }^{8}$ En la mayoría de los casos, en realidad, no se llega ni siquiera a la imposición de una pena privativa de libertad. La multa se ha convertido, desde hace mucho tiempo, en la principal sanción con que son castigados más del $80 \%$

\footnotetext{
${ }^{5}$ En aquel tiempo $\iint 42$ a y ss. StGB (introducidos por la ley para la lucha contra delincuentes habituales y peligrosos [das “Gesetz zur Bekämpfung gefährlicher Gewohnheitsverbrecher”], de 24.11.1933; para esto MülLER (1997), con posterioridad a la reforma al Código Penal $\int S 61$ ss. StGB como "Medidas de corrección y seguridad" (Maßregeln der Besserung und Sicherung). Véase por todos FRISCH, (1990), pp. 343 y ss.

${ }^{6} \mathrm{El}$ internamiento en un centro social-terapéutico, que en un principio fue previsto en el $\int 65 \mathrm{StGB}$ como medida de seguridad nunca entró en vigencia y, con posterioridad, en 1984 fue nuevamente suprimido. Sobre el internamiento de seguridad y su consolidación en los últimos años Cfr. FRISCH (2004), pp. 1-13 con amplias referencias en pp. 12 s.; FRISCH (2002), pp. 669, 679 y ss. así como, últimamente, AlbreCHT (2006), pp. 191 y ss.; FOLKERS (2006), pp. 426 y ss.; LAUBENTHAL (2004), pp. 703 ss.; Milde (2006); STOIBER (2006), pp. 3 y ss.; HARENDORF (2008), pp. 6 y ss. y CEREZO MIR (2008), pp. 405 y ss.; para el correspondiente desarrollo en el ámbito procesal VON FREIER (2008), pp. 273 y ss.

${ }^{7} \mathrm{Y}$, de hecho, ya en los primeros 50 años del Código Penal alemán (StGB); Cfr. sobre esto ExNER (1931), pp. 17 y ss., pp. 20 y ss.

${ }^{8}$ Cfr. EISENBERG (2005), \36 Nm. 6: la relación entre el porcentaje de penas privativas de libertad y de multa se ha invertido en el transcurso de un siglo; sobre el sobreseimiento EISENBERG (2005) \36 Nm. 159; KAISER (1996), § 93 Nm. 24.
} 
de todos los delitos. ${ }^{9}$ La importancia de las penas privativas de libertad es todavía menor si se considera que actualmente, una gran cantidad de casos, a causa de las distintas ampliaciones del principio de oportunidad en el proceso penal, ni siquiera llegan a convertirse en una sanción formal.

c) El camino hacia la moderación, desde luego, no es continuo. En ciertos ámbitos, tanto el legislador como la jurisprudencia, se han aferrado con firmeza a la ejecución efectiva de las penas privativas de libertad y, a decir verdad, en un nivel bastante elevado. ${ }^{10}$ Todavía más: En los últimos años se han producido agravaciones legales de la amenaza penal en algunos ámbitos. A estos pertenecen, en especial, el tráfico de drogas, otros ámbitos relacionados con la criminalidad organizada, delitos de agresión graves y conductas de delincuentes sexuales peligrosos. Frente a una serie de semejantes delincuentes, no solo se produce la imposición de extensas penas privativas de libertad, sino que al mismo tiempo la aplicación de medidas preventivas. ${ }^{11}$

¿Cuál o cuáles son las causas para este cambio manifiesto del derecho penal frente a aquel de la primera época del Código Penal alemán?

\section{Trasfondo social de los cambios en las sanciones penales}

La sustitución de las penas privativas de libertad por la pena de multa puede ser rápidamente aclarada. Esta tiene su razón en la constatación de que, por sobre todo, las penas privativas de libertad de corta duración son frecuentemente mucho más perjudiciales que beneficiosas. Apenas sirven para la seguridad; a menudo -sobre la base del encuentro de primerizos con criminales reales- estas conducen a los principiantes por la senda de la criminalidad. ${ }^{12}$

Más difícil de aclarar es la prolongada tendencia a la moderación en amplias áreas del derecho penal, incluso frente a las sanciones privativas de libertad. Uno podría sentirse inclinado a reducir las razones a la mera sensibilización de la sociedad frente al sufrimiento que se le profiere al delincuente a causa de la pena. De hecho, dicho aspecto ya jugó un papel en relación con la moderación del derecho penal en tiempos previos al actual Código Penal. El hecho

\footnotetext{
${ }^{9}$ Cfr. para esto KAISER (1996), 』92, especialmente Nm. 24 (con estadísticas); GÖPPINGER (2008), \ 34 Nm. 3 y ss. y ALBRECHT (2003), pp. 215 y ss., especialmente p. 217.

${ }^{10}$ Cfr. para eso y lo que sigue Frisch en Albrecht (2003), pp. 155, 179 s.; AlbreCHT (2003), pp. 215, 232 ss., 235 ss. (para violación, Robo con escalamiento y robo cualificado); GÖTTING (1997), pp. 204 ss., pp. 221 ss. (con informaciones sobre "la pena regular" en los distintos delitos); MAURER (2005), pp. 139 ss. (para delitos de drogas).

${ }^{11}$ Cfr. respecto a eso EISENBERG (2005), \ 34 Nm. pp. 62 y s.; FrisCH (2002) pp. 669, 677 y ss.; FRISCH (2004), pp. 1, 4 y s.; KINZIG (1996), pp. 165 ss.

12 Kaiser (1996), \ 93 Nm. 12 y ss.; EISENBERG (2005), 』36 Nm. 12; véase VON LISZT (1905), pp. 290 ss., 353 así como el primer informe escrito (n. 4), pp. 5 y s.; amplias referencias de Frisch en Albrecht (2003), pp. 155, 181.
} 
de que los castigos crueles y degradantes hayan desaparecido en general del catálogo de sanciones se puede atribuir de manera crucial a la humanización del pensamiento y a la, con ella relacionada, sensibilización de la sociedad para con el delincuente que sufre un castigo. ${ }^{13}$ Sin embargo, ese punto de vista no basta para aclarar enteramente la actualidad de la práctica sancionatoria. Esto, porque no aclara por qué la atenuación de las penas es la regla general, pero no la tendencia continua en el derecho penal actual; así como tampoco aclara por qué en determinados ámbitos el derecho penal se aferra totalmente a sanciones elevadas.

La diferenciación se hace más bien explicable cuando se agrega otro punto de vista a estas consideraciones. Este se encuentra ya en ciertos aspectos en el filósofo Hegel. En el apéndice del $\int$ (parágrafo) 218 de la obra "Fundamentos de la filosofía del derecho", este autor afirma que "un Código Criminal no puede tener vigencia para todos los tiempos". Una "sociedad" que de por sí ya es segura, puede reaccionar ante crímenes con menores penas que una sociedad que "en sí misma tambalea”. Este presupuesto para una sanción más atenuada -reconocido claramente por Hegel- vale para un amplio espectro de la criminalidad, por así decirlo, para la criminalidad "normal" - naturalmente difusa en sus límites- que ha existido en todos los tiempos. Frente a eso, la sociedad se siente relativamente segura. Esta forma de criminalidad - este es el sentimiento general de la sociedadse combate también y fundamentalmente con penas suaves o atenuadas. Que esta moderación no tiene como consecuencia un recrudecimiento significativo de la delincuencia, lo demuestra la comparación internacional así como la mirada a los efectos de dichas atenuaciones anteriores. ${ }^{14}$ Responde también a conocimientos criminológicos. Para el mantenimiento de la conciencia jurídica y, al mismo tiempo, para la prevención es suficiente -en general- que se reaccione por medio de la pena; su cuantía tiene más bien una importancia secundaria. ${ }^{15}$

Naturalmente, esto tiene solo una validez general, es decir, únicamente en la medida en que una pena leve sea aceptada como reacción adecuada al hecho y, al mismo tiempo, la sociedad pueda asegurarse de sí misma con la imposición de dicho tipo de sanciones. La cuestión cambia, sin embargo, en la medida en que se trate de hechos en los que la sociedad se siente masivamente amenazada y frente a los cuales, con la irrogación de dichas sanciones leves, de ninguna manera se pueda estar seguro. Este es el caso -al menos en Europa- para el tratamiento de hechos

13 Cfr. GÖppinger (2008), \ 34 Nm. 8 y ss.; SCHMidT (1965), pp. 216, 218, 220 y s. (sobre la influencia de la ilustración, que por supuesto ve racionalmente también los peligros de los castigos crueles).

14 Así, por ejemplo, la comparación entre países de una estructura de población similar, específicamente los países nórdicos, ha mostrado que sin duda cambios importantes en el uso de las penas privativas de libertad no habían producido cambios esenciales en los índices de criminalidad; Cfr. LAPPI-SEPPÄLÄ (2003), pp. 261, 282 y s.

${ }^{15}$ Cfr. en especial, la idea de una cierta intercambiabilidad de las sanciones; para eso KAISER (1979), pp. 923, 938; KAISER (1996), § 31 Nm. 34, \ 91 Nm. 4; SCHÖCH (1973), pp. 86 y s., pp. 198 y s. 
relacionados con la delincuencia organizada, el narcotráfico, la criminalidad violenta grave o los delincuentes sexuales peligrosos, etc. Frente a estos delincuentes, la sociedad espera una protección efectiva. Las penas elevadas -que habitualmente se imponen frente a esta clase de criminalidad y que en los últimos años han sufrido una agravación mayor- responden a esa necesidad, al igual que la aplicación intensificada de medidas preventivas frente a determinados grupos de delincuentes. Naturalmente, con esta aclaración psicológico-social de las sanciones penales elevadas frente a determinados hechos o grupos de delincuentes, a pesar de la tendencia general hacia la moderación de las penas, no se ha dicho nada respecto de la legitimidad de esa penalización elevada. Solo se ha aclarado la interrogante referida a por qué una determinada transformación del derecho producida socialmente, esto es, su atenuación, no ha incidido en el tratamiento de ciertos hechos. Con todo, esta limitación responde a que en nuestro tratamiento del tema solo se plantea la interrogante sobre la conexión entre la transformación social y la transformación del derecho y no por la legitimidad de esa transformación y sus límites. Cabe señalar, en todo caso, que bajo el aspecto de la legitimación no es posible objetar la aplicación de penas altas y la no atenuación (por lo demás justificable), en la medida en que la sanción penal elevada responde al significado del hecho por el quebrantamiento del ordenamiento jurídico y a su peligrosidad social y exista un fundamento (en protección de la sociedad) para aplicar completamente la pena justa (y no -como en los demás casos- para su moderación). ${ }^{16}$

\section{Transformación en el ámbito de los delitos en particular}

Estos cambios trascendentales no solo se evidencian en lo relativo a las sanciones. También han sufrido modificaciones significativas tanto el catálogo de delitos en particular como su calificación y jerarquía. Esto no solo vale en relación con los Códigos de la edad media y los de comienzo de los tiempos modernos que contenían delitos (como la blasfemia, brujería, hechicería, etc.) basados en concepciones teocráticas de la sociedad y del Estado y que hoy nos parecen completamente ajenas. ${ }^{17}$ Por el contrario, este análisis tiene validez también en relación con el Código Penal alemán (StGB) entrado en vigencia en 1871.

\section{Panorámica general de algunos de los cambios más importantes}

El Código Penal alemán de 1871 contiene una serie inmensa de tipos delictuales que a lo largo de los tiempos ha sido suprimida. Ejemplos conocidos son el adulterio, una lista de los llamados delitos contra la moral (homosexualidad,

\footnotetext{
16 Véase para tal efecto (bajo la apreciación de la jurisprudencia del Tribunal Federal Alemán o BGH) detalladamente FRISCH (2000b), pp. 269, 270 y ss., pp. 282 y ss., pp. 302 y ss.

${ }^{17}$ Cfr. para eso SCHMIDT (1965), pp. 209 y ss.
} 
sodomía, etc.), el duelo, así como también el amplio grupo de las faltas penales. ${ }^{18}$ Por otro lado, el Código Penal actual contiene un no despreciable número de delitos que para el Código Penal de 1871 eran completamente desconocidos. Con el correr del tiempo se han agregado como tipos penales distintos delitos similares a la estafa (como la estafa informática, de créditos, de subvenciones, etc.), la falsificación y manipulación de registros técnicos o tecnológicos, el lavado de dinero, la formación de organizaciones criminales y terroristas, el secuestro extorsivo de personas, toma de rehenes y muchos más. ${ }^{19}$

Esta transformación en los delitos se manifiesta, sin embargo, no solo en nuevas incorporaciones y eliminaciones de tipos penales. También son rasgos característicos de esta transformación del derecho penal, en el ámbito de los delitos en particular, las modificaciones relativas a la calificación y jerarquía de ellos. Delitos como los contra el medio ambiente fueron incorporados al derecho penal nuclear para expresar su importancia también simbólica, parcialmente reducidos y con elevadas amenazas penales. ${ }^{20}$ Delitos contra las personas como el delito simple de lesiones, que por largo tiempo fueron ubicados por debajo de los delitos contra la propiedad y cuya tentativa ni siquiera era punible, fueron clasificados de manera más elevada. Pero los que, ante todo, experimentaron una nueva valoración han sido los llamados delitos de agresión (Aggressionsdelikte) como las formas graves de lesión corporal y delitos sexuales relacionados con violencia así como también los delitos cometidos por bandas, de manera profesional y organizadamente, lo que se ve reflejado en una agravación de la amenaza penal así como en la creación de nuevos tipos penales y cualificaciones. ${ }^{21}$

\section{Trasfondo social del cambio}

El trasfondo de estos y una serie de otros cambios en el derecho está constituido, sobre todo, por las transformaciones en el ámbito social. Aquí se incluye, por supuesto, aquello que se ha transformado y aquello que se anhela de los cambios del derecho, en niveles totalmente diferentes.

18 Cfr. del Código Penal alemán (StGB) de 1871 el \172 (adulterio), \ 175 (homosexualidad,

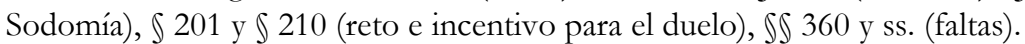

${ }^{19} \mathrm{Cfr}$. en algo hoy el $\ 263$ a StGB (estafa por computadoras), \264 (estafa de subvenciones), \265 b (estafa de créditos), \ 268 así como también el \ 274 Abs. 1 Nr. 1 (falsificación y manipulación de

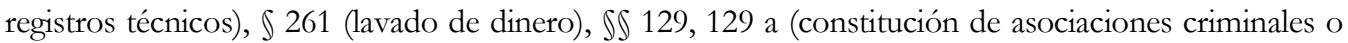
terroristas), $\iint 239$ a y b (el secuestro extorsivo de personas y toma de rehenes).

20 Véase para eso detalladamente el proyecto de Ley para la lucha contra la criminalidad medio ambiental (Entwurf eines Gesetzes zur Bekämpfung der Umweltkriminalität) (18. StrÄG), Allgemeine Vorbemerkungen, N.4, BT-Drucks. 8/2382; FRISCH (2000a), pp. 361 y s. con amplias referencias; KÜHL (1987), pp. 815, 817.

${ }^{21}$ Detalladamente sobre otras leyes y modificaciones en particular FRISCH (2002) pp. 669, 677 y ss., 682 y ss. con amplias referencias. 
a) Las transformaciones, en principio, pueden ser apreciadas en el ámbito de las concepciones, de las representaciones de valor y en las escalas de valoración. La sociedad se ha vuelto más tolerante en la valoración de determinados modos de conductas consideradas antes como desviadas, ofensivas y merecedoras de pena. Al mismo tiempo, la sociedad se ha vuelto más cautelosa frente a la desaprobación de tales modos de comportamiento, al menos frente a su calificación como conducta merecedora y necesitada de pena. Esta es la razón por la cual hoy en día hayan desaparecido determinados delitos que se encontraban contenidos en el Código Penal de 1871 e incluso todavía en el proyecto de Código Penal de 1962, como el adulterio o determinados delitos contra la moral. Lo mismo sucede con la supresión de las faltas penales como hechos punibles más leves, cuya eliminación se basó en el supuesto de la falta de merecimiento de pena de las conductas desviadas de baja cuantía. ${ }^{22}$

Por otra parte se han modificado, también en este aspecto, los parámetros valorativos de la sociedad en tanto se han ido considerando de modo paulatino ciertos modos de conducta dignos de reprobación y merecedores de pena que el legislador liberal de 1871 no había considerado tales. O también cuando en la actualidad se ponderan ciertos modos de comportamiento claramente como más dignos de pena que en decenios anteriores. La revalorización de los delitos contra las personas, por ejemplo, responde a una concepción (crítica) -fundamentada también en la Constitución con el lugar prioritario que ocupa la persona humana y el reconocimiento de su dignidad- que entiende que el legislador del Código Penal (StGB) habría valorado insuficientemente los bienes de la persona (Persongüter). La clasificación que confiere mayor peso a los delitos contra el medio ambiente tuvo lugar después de que la sociedad tomó dolorosamente conciencia acerca de cuán vulnerables eran los bienes medioambientales y del grado de dependencia en que se encontraba la persona humana en relación con un medioambiente intacto. Se trata de una idea que incluso ha llevado al legislador constitucional alemán a complementar la Constitución en el art. 20 a de la Ley Fundamental (GG) a través de una disposición que fija un objetivo estatal dirigido a la conservación del medio ambiente.

Obviamente detrás de estas nuevas valoraciones en los delitos existentes y en la creación de nuevos delitos no hay únicamente concepciones modificadas relativas al rango de valor y a la importancia de los bienes. Otras concepciones también han sufrido cambios que producen efectos sobre el derecho penal. La sociedad (no solo) se ha vuelto más tolerante, sino que también más solidaria. Esta considera al individuo no solo como persona frente a la cual los otros no tienen el derecho a lesionar sus bienes, sino que también como persona que tiene el deber de ayudar a dichos otros cuando se ven enfrentados a peligros de gravedad. La

\footnotetext{
${ }^{22}$ Sin embargo, no se suprimió la sanción para una serie de tales faltas. Estas antiguas faltas penales son, hoy en día, contravenciones administrativas sancionadas con multas administrativas.
} 
sociedad va incluso tan lejos que valora como merecedora de pena la omisión de tal asistencia (y para tal comportamiento exige la imposición de una pena): ${ }^{23} \mathrm{Se}$ trata de una concepción que era todavía muy lejana para el legislador del siglo XIX, el que respondía a concepciones sociales completamente diferentes y al concepto de Derecho del liberalismo.

b) Por cierto, no solo las transformaciones en el ámbito de las concepciones sociales han sido y son de relevancia para el derecho penal. Un rol esencial juegan también los cambios relacionados con las condiciones materiales de la sociedad. El mundo ha sido modificado sosteniblemente por los desarrollos tecnológicos e investigaciones científicas en los diferentes campos. Objetos de reciente desarrollo han abierto de manera fecunda nuevas posibilidades de acción, pero, al mismo tiempo, han creado nuevas contingencias de ataque para los bienes jurídicos existentes y nuevas posibilidades de ser utilizados en un modo peligroso o abusivo para dichos bienes. De manera completamente equivalente pueden ser utilizados los resultados obtenidos por la investigación científica, vale decir, de un modo fructífero y orientado al bien común, pero también de un modo que puede ser peligroso para dichos bienes o considerado problemático a causa de lo imprevisible o lo indeseado de sus consecuencias. ${ }^{24}$ Es evidente, entonces, que ni el derecho ni el derecho penal se pueden mantener inactivos frente a tales puestas en peligro y posibilidades de abuso.

Para esto no siempre se requerirá impulsar modificaciones a la ley vigente o proponer la creación de nuevas leyes. En muchos casos, para afrontar dichos peligros y recientemente abiertas posibilidades de abuso, se puede considerar la posibilidad de una nueva aplicación de la ley vigente, probablemente por medio de una interpretación extensiva. Ante todo, los delitos comunes de resultado (no limitados a una determinada forma de acción) ofrecen, en esta medida, alternativas. ${ }^{25}$ Pero, por lo demás, la jurisprudencia también ha encontrado medios y vías para salir al paso de estas nuevas posibilidades de acción y de peligros, ya mediante la aplicación del derecho vigente. ${ }^{26}$ Por supuesto que las posibilidades de

${ }^{23}$ Cfr. $\int 323$ c StGB: punibilidad de la denegación de auxilio, cuando la prestación de auxilio "en catástrofes o peligro o urgencia pública sea indispensable y según las circunstancias le sea exigible”.

${ }^{24}$ Como ejemplo de lo anterior, la posibilidad de la ingeniería genética y la experimentación con células madres humanas.

25 Es de recordar la capacidad de rendimiento de estos delitos en la comprensión de la denominada responsabilidad penal por el producto; véase sobre esto, en lugar de todos, con una mirada a la jurisprudencia y la literatura penal KUHLEN (2000), pp. 647 y ss.

26 Así, por ejemplo, se considera como un documento también las declaraciones contenidas en un computador, que una persona se hace así misma (Cfr. OLG Köln NJW 2002, 527; FISCHER (2008), \267 Nm. 3), o la utilización de una copia en \267 StGB, cuando por ese medio indirectamente se hace uso de un instrumento falsificado (BGHSt 5, 291, 293; 24, 140, 142; amplias referencias en FISCHER (2008), Nm. 24), de la misma forma el uso de una copia presentada como presuntamente original. (BayObLG NJW 1992, 3311). Véase. PuPPE (2000), pp. 569 y ss. 
la jurisprudencia no son ilimitadas, especialmente en el derecho penal a causa de su prohibición de aplicación de la analogía. Los modos de conducta, que por medio de los recientes desarrollos y objetos han abierto nuevos peligros para los bienes, pueden hasta ahora responder a modos de comportamiento que ya están contemplados penalmente: si estas conductas no pueden ser subsumidas al tenor literal de las leyes existentes, significa que no están abarcadas por el derecho penal vigente. Con mayor razón vale esto para nuevos peligros que, hasta ahora, no han sido considerados legalmente, debido a que no existían las correspondientes posibilidades de riesgo (como en los casos de la investigación e ingeniería genética). En casos de ese tipo, los nuevos peligros solo pueden ser abarcados por medio de una intervención del legislador.

La labor del legislador no representa ninguna gran dificultad allí donde, en lo esencial, de lo que se trata es de incorporar modos de conductas que ya son comprendidos funcional y valorativamente en la ley vigente, pero que no están cubiertos por el tenor literal de la misma. Aquí, por regla general, será suficiente con actualizar el derecho hasta ahora existente, de manera que los modos de comportamiento todavía no comprendidos en los tipos penales vigentes sean incorporados en estos o que para aquellos se incorporaren nuevos tipos penales. Para este último objetivo, la medida la constituye la identidad valórica entre la nueva conducta y la ya comprendida. Típicos ejemplos para tales actualizaciones lo constituyen la complementación al tipo penal de la estafa mediante la llamada estafa informática o la adaptación de los llamados delitos documentales por medio de los delitos de o contra la manipulación de "registros técnicos o tecnológicos", junto a los cuales se encuentra también la adaptación del delito de daños a la propiedad por medio del delito de daños o destrucción del almacenamiento de datos, o también la introducción de seguros más allá de los de contra incendio y para embarcaciones en el fraude de seguros, o la inclusión del incendio (Brandlegung) en los delitos de provocación de incendio. ${ }^{27} \mathrm{Si}$ se examinan minuciosamente las modificaciones al Código Penal alemán (StGB), desde su entrada en vigencia, se puede establecer que existe un gran número de modificaciones que corresponden a tales actualizaciones.

Más compleja se vuelve la "empresa" del legislador cuando ya no se trata solamente de una adaptación, sino que de considerar nuevas formas de puestas en peligros, para las cuales hasta ahora se carece de algo comparable. Típicos ejemplos lo representan las posibilidades abiertas por la medicina reproductiva o ciertas posibilidades de la investigación técnicamente existente así como del trato con genes humanos. Los peligros, de los que aquí se trata, caen fuera del espectro de los bienes y peligros comprendidos por los tipos penales tradicionales; estos peligros se refieren a los objetos no protegidos todavía y, en parte también, a los

${ }^{27}$ Cfr. sobre los delitos nombrados en el texto, en el orden de precedencia $\iint 263$ a, 268, 303 a, 265, 306 y ss. del actual Código Penal alemán (StGB). 
peligros actualmente difíciles de valorar. ${ }^{28}$ Con el intento de separación (Abschichtung) de los modos de conducta permitidos de aquellos no permitidos e, incluso, de los ya amenazados penalmente en estos ámbitos, el legislador ingresa en nuevos territorios. La solución de la tarea asignada no se dificulta solamente por el hecho de que los correspondientes modos de conducta sean valorados de manera muy diferente desde el punto de vista moral. ${ }^{29}$ Las opiniones sobre los posibles beneficios alcanzables por medio de los respectivos modos de comportamiento y de los peligros relacionados con ellos se encuentran también divididas. $^{30}$ Así como también se encuentran divididas las opiniones sobre lo deseable o indeseable de las consecuencias de tales modos de conducta. Frente a tanta controversia e incertidumbre, ya en el ámbito de los factores y criterios de valoración que sirven por base para fundamentar la ley, en última instancia, tampoco se puede descartar que la solución legal ${ }^{31}$ sea objeto de controversia y que presente rasgos de un experimento legal que posiblemente requiera ser revisado. Habría que mencionar que, en el fondo, aquí el debate no se refiere primeramente a la conminación penal de determinados modos de conductas, sino ya a su desaprobación legislativa. Se trata básicamente ya de un problema atinente al orden primario prepenal que solo atraviesa al derecho penal.

c) Entre tanto, no solo se evidencian transformaciones en el ámbito de las condiciones materiales y potencialidades de la sociedad, que son las que forman las bases para una vida próspera en comunidad y que naturalmente también pueden ser susceptibles de abusos. Adicionalmente se ha transformado una parte de la

${ }^{28}$ Cfr. al respecto SCHREIBER (2001), pp. 891, 893 y ss.

${ }^{29}$ Cfr. al respecto en DutTGE (2002), pp. 241, 249 y ss.; SCHREIBER (2001), pp. 891, 893 y s. También en las comisiones de ética y consejos de ética fueron representadas posturas controvertidas sobre las interrogantes pertinentes (ej. El diagnóstico preimplantacional, la investigación de y con células madres).

${ }^{30}$ Mientras algunas personas creen en la posibilidad de una ganancia de nuevos conocimientos para la cura de enfermedades, hasta ahora incurables, otros ven, en el mejor de los casos, una vaga posibilidad e indican los peligros incalculables de tales desarrollos. Cfr. para eso SCHULZ (2003), pp. 362, 364 y ss. con amplias referencias.

${ }^{31}$ Cfr. al respecto para Alemania $\int 1$ y $\int 2$ de la Ley para protección de embriones (Gesetz zum Schutz von Embryonen) de 13.12.1990 y de 23.10.2001, BGBl. 2001 I p. 2702 (sobre los abusos penalizables del uso de medicina reproductiva y sobre el uso abusivo de embriones humanos), $\iint 5$ - 7 de la misma ley (sobre la punibilidad de la manipulación artificial de células humanas en estado germinal, de la clonación humana y de la creación de quimeras o híbridos); véase además la Ley para garantizar la protección de embriones humanos en relación con la importación y uso de células madres humanas (Ley de células humanas - Stammzellgesetz) de 28.6.2002 (BGBl. 2002 I, p. 2277 y BGBl. 2003 I, p. 2304, 2306), que posibilita la importación y uso de células madres humanas bajo ciertos requisitos ( $\iint 4$ y 5 de la ley) y que sanciona penalmente en el $\int 13$ la importación y uso sin el permiso exigido en el $\$ 6$. Véase por todo lo relacionado DUTTGE (2002), pp. 241 y ss.; RENZIKOWSKI (2001), pp. 2753 y ss.; SCHROTH (2002), pp. 170 y ss. Así como SCHREIBER (2001) y SCHULZ (2003); sobre nuevos problemas de la ley sobre protección de embriones humanos (Embryonenschutzgesetz) LILIE (2007), pp. 305 y ss. con amplias referencias. 
sociedad que de todos modos ya había sido calificada negativamente: la manera y la forma de aquello que el derecho vigente ya define como delito. En algunos ámbitos esta criminalidad ha devenido notoriamente más masiva, brutal y peligrosa. Más brutal y peligrosa es la comisión de ciertos delitos de agresión como las lesiones corporales, delitos sexuales violentos así como los delitos violentos contra la propiedad. La criminalidad por sobre todo en el ámbito de los delitos contra la propiedad y delitos de enriquecimiento, en el comercio ilegal de armas, de drogas y también de personas, ha logrado otra dimensión mediante su comisión por medio de bandas $\mathrm{u}$ organizaciones dirigidas rígidamente. Estas organizaciones se mantienen comúnmente intactas en su núcleo, aún después de la detención de algunos de sus miembros. Así, por medio de la comisión constante de delitos graves logran infligir daños de consideración a los individuos y a la sociedad. Al mismo tiempo, las cuantiosas ganancias conseguidas por medio de la criminalidad organizada son, permanentemente, difíciles de rastrear una vez que se han aclarado los hechos. Estas son invertidas, sujetas a movimientos y transformaciones, de tal manera que legalmente no es posible "comprobar su origen". 32

Estas evoluciones del lado oscuro de la sociedad, vale decir, de la misma criminalidad, han provocado una transformación considerable del derecho penal, quizás incluso de la manera más evidente. Conforme a la opinión de algunos se ha producido una deformación del derecho penal como sobrerreacción a estas transformaciones del fenómeno social de la criminalidad. El catálogo de modificaciones en el derecho penal, que pueden ser atribuidas a la evolución misma de la criminalidad, es extenso. ${ }^{33}$ Dignas de mención son el endurecimiento de los tipos penales ya existentes y sus cualificaciones como también la creación de nuevos tipos penales cualificados. ${ }^{34}$ Como reacción a determinadas y relativamente nuevas formas de criminalidad masiva se han introducido - en gran parte nuevostipos delictivos especiales, en un lugar destacado, como por ejemplo, el secuestro con extorsión o la toma de rehenes. ${ }^{35}$ Estos nuevos tipos penales adelantan, a menudo, la realización consumada del tipo en estados ampliamente previos. En el caso del secuestro con extorsión, por ejemplo, se califica una mera detención ilegal, que se presenta como preparación planificada para una extorsión,

32 Véase en relación con el párrafo anterior y con amplias referencias, FRISCH (2002), pp. 669, 682 y ss.; detalladamente y en extenso KINZIG (2004).

33 Detalladamente en KINZIG (2004), pp. 164 y ss. (para el derecho material) y 102 ss. (para el derecho procesal).

${ }^{34}$ En el StGB se han aumentado las amenazas penales sobre el abuso sexual de niños ( $\int 176-\int 176$ b StGB), sobre determinados delitos de lesiones físicas (por ejemplo, las lesiones corporales peligrosas, \$224; maltrato de sujetos en custodia \$225; lesión corporal grave \$226). - Se han creado nuevos tipos penales, por ejemplo en el ámbito de la grave criminalidad contra la propiedad ( $\$ 244$ a: hurto grave en bandas), además se crearon varias clasificaciones para delitos cometido en banda (por ejemplo, \$260 a: receptación profesional por bandas; \$146 parr.2: falsificación de dinero cometido en banda); véase también KINZIG (2004), pp. 171 y ss.

35 Cfr. $\int 239$ a (secuestro con extorsión) y $\int 239$ b StGB (toma de rehenes), introducido por la 12. Ley modificatoria penal (Strafrechts-Änderungsgesetz) de 1971. 
precisamente por ese trasfondo como uno de los delitos consumados más graves. En otros ámbitos, que típicamente se atribuyen a la criminalidad de bandas o a la criminalidad organizada, se sancionan crecientemente meros actos preparatorios para delitos planificados, con penas bastante severas. ${ }^{36}$ Aún más adelantada se encuentra la punibilidad en aquellos tipos penales que ya consideran la pertenencia a determinadas asociaciones (criminales o terroristas) como un comportamiento delictual. $^{37}$

Desde luego, las medidas con que la ley (sobre todo) intenta contrarrestar las formas de criminalidad organizada y terrorismo no se agotan en la creación de nuevos tipos penales que persiguen captar la conducta de los autores de la criminalidad organizada misma, como tampoco con el adelantamiento y la agravación de los tipos penales pertinentes.

Un rol esencial cumple en concepto del legislador la idea de que se debe impedir que los delincuentes puedan aprovecharse de las ganancias provenientes de la mencionada criminalidad y, al mismo tiempo, se debe afectar la motivación para la comisión del hecho delictivo. Esto se lograría mediante la imposición de gravámenes a su ganancia. A esta idea no solo responden las diferentes ampliaciones de la posibilidad del comiso. ${ }^{38}$ En este contexto se deben analizar los recientemente creados tipos penales de lavado de dinero: estos pretenden dificultar a los delincuentes de la criminalidad organizada la posibilidad que puedan hacer uso e inversión de las ganancias obtenidas a causa de la comisión de sus delitos. Esto, mediante la prohibición a terceros, bajo amenaza de (importantes) penas, de ocultar, aceptar, transformar en otros valores, etc., los frutos del delito (y de esa manera "lavarlos"). ${ }^{39}$ Este amplio concepto legal-material se complementa con medidas procesales.

\section{Cambios en el ámbito procesal (o del proceso)}

El proceso penal alemán ha experimentado también diversas modificaciones en los últimos decenios. No todos esos cambios expresan el cambio social, pero naturalmente hay modificaciones que están relacionadas tanto con una

\footnotetext{
36 Cfr., por ejemplo, $\int 149$ StGB (preparación para falsificación de dinero y sellos).

${ }^{37}$ Cfr. $\int 129$ (constitución y participación en organizaciones criminales); \129 a StGB (formación o participación en organizaciones terroristas). En general y fundamentalmente sobre el tema del adelantamiento de la punibilidad: JAKOBS (1985), pp. 751 y ss.; HASSEMER (1989), pp. 553 y ss.; KEMPF (1997), pp. 1729 y ss. Sobre el injusto de la asociación criminal CANCIO (2007), pp. 27 y ss.

38 Véase especialmente $\int 73 \mathrm{~d}$ StGB y para ello y detalladamente (respecto de la criminalidad organizada) KINZIG (2004), pp. 211 y s.

39 Cfr. particularmente $\int 261$ StGB y para su importancia en la criminalidad organizada (críticamente) KINZIG (2004), pp. 209 y ss.
} 
transformación de la sociedad como de las visiones de esta. Para ello, se pueden nombrar cuatro ejemplos:

\section{Modificaciones a la etapa previa al juicio: "Policialización" (Verpolizeilichung)}

La etapa previa del proceso penal ha sufrido modificaciones sustanciales. Ha dejado, ya desde hace un tiempo, de estar en manos del denominado en Chile "Ministerio Público" o "Fiscalía", pasando a formar parte de las facultades de la Policía. ${ }^{40}$ En este sentido, incluso ya se puede hablar de una "policialización" de la etapa previa al juicio. ${ }^{41}$ Pero este concepto puede tener, además, otro sentido. Se puede hablar también de "policialización" en el sentido de los métodos utilizados. Debido a la introducción de diversos medios intrusivos y medidas de investigación en muchos países europeos, el proceso penal y, sobre todo, las diligencias previas al juicio presentan cada vez más rasgos de vigilancia policial. Se han sumado al allanamiento, registro de vestimentas e incautación otras medidas como la pesquisa mediante rastreo o combinación de datos (Rasterfahndung), la pesquisa por medio del rastreo y almacenamiento de datos frente a la sospecha de comisión de delitos (Schleppnetsfabndung), la vigilancia telefónica, la vigilancia de espacios habitados, las observaciones, el empleo de agentes encubiertos, etc. ${ }^{42}$ Estos métodos han sido muy utilizados en determinados procesos, en especial, en aquellos relacionados con el narcotráfico u otras formas de la criminalidad organizada. ${ }^{43}$ No en pocas ocasiones la policía desarrolla investigaciones, incluso antes que se haya hecho uso del instrumental de la ordenanza procesal penal alemana (StPO), para lo cual se basa, principalmente, en sus facultades policiales (preventivas). Uno que otro habla, en este sentido, de un preproceso o diligencias en el campo previo a la verdadera investigación, lo que, actualmente, sería típico en la persecución de determinadas formas de criminalidad. ${ }^{44}$

\footnotetext{
40 Para el trasfondo de esta evolución, cfr. p. ej. Roxin (1998), \10 Rn 34 f.

41 En relación con la "policialización" de las etapas previas al proceso penal, véase KINZIG (2004), especialmente pp. 87 y s., p. 125 (explicación del concepto), 133 ff., 790 f.; PAEFFGEN (1995), S. 13 ff.; véase también PAEFFGEN (2003), 647 y ss.

42 Para la pesquisa mediante rastreo o combinación de datos (Rasterfahndung), Cfr. \$S 98 a - c StPO, la pesquisa a través del rastreo y almacenamiento de datos frente a la sospecha de comisión de delitos (Schleppnetzfahndung) \ 163 d StPO, para la vigilancia telefónica $\iint 100$ a y b StPO, para la vigilancia espacios habitados con escuchas y grabación (conforme a BVerfGE 109, 279 y ss.) $\int 100$ c (y LÖFFELMANN (2005), pp. 2033 y ss.), para observaciones de largo plazo $\int 163$ y s. StPO (las observaciones de corta duración están comprendidas en $\int 163$ párr.1 2a frase; MEYERGOSSNER (2008), \ 163 f Nm. 1), en cuanto a la utilización de agentes encubiertos \$S 110 a - $110 \mathrm{c}$ StPO; y en cuanto a la utilización no regulada de los denominados hombres V ("vigilancia") ROXIN (1998), 』 19 Nm. 25 y ss.

43 Véase KINZIG (2004), pp. 427 y ss., especialmente. 443 y ss.

${ }^{44}$ Cfr. KINZIG (2004), pp. 427 y ss.; también ERB (2008), observaciones previas al $\int 158$ Nm. 9 y ss. con amplias referencias.; WESSLAU (1989); LANGE (1999).
} 
La modificación descrita, relativa a la etapa previa al proceso penal, en el caso de la persecución de determinadas formas de criminalidad, no es casual. También se trata de la reacción a un cambio de la realidad social. Se trata de la respuesta del Estado a la creciente amenaza de la sociedad, mediante determinadas formas de criminalidad, sobre todo frente a determinadas manifestaciones de la denominada criminalidad organizada. Sin el uso de estos métodos más modernos de vigilancia e investigación -se dice- el esclarecimiento exitoso de determinadas formas de criminalidad sería, de antemano, imposible. ${ }^{45}$ Algunos hablan, en este contexto, más claramente de una lucha contra la criminalidad, ${ }^{46}$ mientras que otros ven aquí rasgos del denominado "derecho penal del enemigo". ${ }^{47}$ La crítica desecha parcialmente estos $\operatorname{conceptos}^{48} \mathrm{y}$, no pocas veces, se vuelve en contra de las medidas extendidas o, al menos, de una parte de ellas. ${ }^{49}$ Lo que en este caso es correcto puede quedar abierto a la discusión en el marco de esta reflexión ya expuesta. En todo caso lo que es seguro es que aquí los cambios de la realidad social junto con las preocupaciones y expectativas han provocado una modificación significativa en el proceso penal.

\section{Fortalecimiento de los derechos de la víctima}

Si se regresa a los procesos penales normales, es posible observar cambios sustanciales en lo relativo a los sujetos que intervienen en el proceso. La víctima, que durante mucho tiempo fue ubicada en un plano secundario del proceso penal, hoy en día ha sido nuevamente descubierta. Ya no está involucrada meramente como un testigo o, en ciertos casos, en su rol procesal como acusador particular o querellante, como un interviniente en el proceso con facultad para formular solicitudes. También posee, más allá de los estrictos requisitos de la querella, más derechos en el proceso. Puede revisar las actas, participar en el juicio con asistencia de un abogado, tiene derecho a ser informada y puede hacer valer sus pretensiones sobre el hecho durante el juicio. ${ }^{50}$ En algunos países, los respectivos derechos van

\footnotetext{
45 En este sentido, la fundamentación a la ley para la lucha contra el tráfico ilegal de drogas y otros tipos de criminalidad organizada (OrgKG), BT-Drucks. 12/989, p. 1, 21, 40.

46 Así, el mismo legislador con la calificación de la ley del 15 de julio de 1992 como "Ley sobre la lucha contra la criminalidad organizada", y de la ley del 28 de octubre de 1994 como "ley de la lucha contra la criminalidad", véase BGBl 1992 I p. 1302 como también 1994 p. 3186.

47 Para esta terminología véase especialmente JAKOBS (1985), pp. 751, 757 y ss. y últimamente JAKOBS (2005), pp. 839, 845 y s., 846 y ss. En cuanto al debate: CANCIO (2005), pp. 267 y ss.; HÖRNLE (2006), pp. 80 y ss.; GRECO (2006), pp. 96 y ss.; GÖSSEL (2006), pp. 33 y ss.; SALIGER (2006), pp. 756 y ss. y PÉREZ DEL VALLE/POLAINO (2007), pp. 515 y ss. como también pp. 529 y ss.

48 Cfr., por ejemplo, EsER (2000), pp. 437, 445; ALBRECHT (2005), pp. 852, 855 y ss.; GÖSSEL (2006), pp. 33 y ss.; SALIGER (2006), pp. 756 y ss., p. 762.

${ }^{49}$ Cfr., por ejemplo, la crítica a la ley para la lucha contra el tráfico ilegal de drogas y otras formas de la criminalidad organizada (OrgKG) por KREY/HAUBRICH (1992), pp. 309 y ss.; MEERTENS (1992), pp. 205 y ss.; STRATE (1992), pp. 29 y ss. y KINZIG (2004), pp. 105 y s. Para la crítica del "Lauschangriff” LEUTHEUSSER-SCHNARRENBERGER (1998), pp. 87 y ss.; DiTTRICH (1998), pp. 336 y ss.

${ }^{50}$ Cfr. para ello $\iint 403$ - 406 c (reclamación de los derechos frente al acusado en el juicio penal), $\int$ 406 d (derecho a información), \406 e (posibilidad de revisar actas por el abogado), \406 y s
} 
incluso sustancialmente mucho más allá que lo dispuesto en el proceso penal alemán. ${ }^{51}$

En este contexto, se reflejan en estos cambios procesales transformaciones en la forma de entender la función del proceso penal. Las ideas en que se basa esta evolución del significado de la función corresponden solo en parte al resultado de una teorización jurídica. En primera línea, estas emanan de la sociedad. Se trata, en una no despreciable parte, de concesiones a las asociaciones de víctimas y a la opinión pública en el sentido que el Estado, el derecho penal y el derecho procesal penal no se preocupan suficientemente por el bienestar y los justificados intereses de las víctimas. ${ }^{52}$ Las respectivas reflexiones no se restringen al ámbito procesal, sino que además poseen un paralelo en el derecho material, en forma de la denominada Conciliación-Autor-Víctima (Täter-Opfer-Ausgleich). ${ }^{53}$ No obstante, todo lo que prevé la ley en lo relativo a la víctima en el ámbito procesal y legalmaterial, en opinión de algunos, representa mucho menos de lo que se desearía. ${ }^{54}$ Es por esta razón que no se pueda descartar, en este ámbito, que se producirán todavía más modificaciones, que consideran la transformación de las concepciones sociales sobre la importancia de la víctima en y para el proceso penal.

\section{Cambios en el derecho probatorio: prohibiciones probatorias}

Una parte esencial del proceso penal ha sido objeto de modificaciones significativas en el transcurso del último siglo: el derecho probatorio. Para el actual derecho probatorio procesal penal alemán es característico, entre otras cosas, el constituir un sistema altamente diferenciado de prohibiciones probatorias. La misma ley ya contiene diferentes prohibiciones de obtención de pruebas y de utilización de pruebas. La jurisprudencia ha añadido a estas prohibiciones probatorias de carácter legal, además, una cantidad de otras que no solamente impiden el uso de determinadas pruebas recogidas erróneamente, sino que excluyen absolutamente a ciertos medios de prueba del proceso penal. ${ }^{55} \mathrm{Si}$ se compara este sistema diferenciado de prohibiciones con la situación existente hace

(posibilidad de contar con un abogado durante el juicio). Especialmente para la indemnización de las víctimas de actos violentos, véase la ley de indemnización para víctimas de delitos violentos de 7.1.1985 (BGBl 1985 I p. 1) y ROXIN (1998), \ 58 con amplias referencias.

51 Para ello, véase la extensa comparación de los derechos de las víctimas en el proceso penal en Alemania, Francia y Estados Unidos en: STEHLE (2006), pp. 70 y ss.

52 Cfr. para ello, por ejemplo, "Rechtspolitischen Forderungen" des Weißen Rings (en: www.weisser-ring.de)

${ }^{53}$ Cfr. $\int 46$ a StGB, según la cual se retribuye el acuerdo deseado del delincuente con la víctima (en el sentido de la reparación del acto y sus consecuencias) con una moderación facultativa de la pena o en algunos casos, incluso, con la prescindencia de ella. Más detalles en SCHÖCH (2000), pp. 309 y ss.

${ }^{54}$ Cfr. WALther (2000), pp. 157 y ss., 297 y ss.

55 Panorámica sobre la jurisprudencia y literatura referidas a las prohibiciones de prueba en ROXIN (1998), \ 24 D (Nm. 13 - 48); presentación detallada en JäGER (2003). 
cien años, se puede ver claramente que, en este punto, el proceso penal ha sufrido notables cambios. ${ }^{56}$

Las razones que explican estos importantes cambios radican en una transformada perspectiva de la relación entre los derechos del acusado y los intereses en la persecución penal. El acusado se ha convertido, cada vez más, en un sujeto procesal. Si bien ya la ordenanza Procesal Penal alemana (StPO) del siglo XIX y, sobre todo, la ordenanza procesal del Reino (RStPO) de 1877 se basaban notablemente en esta posición del acusado como sujeto procesal, el pleno reconocimiento de tal posición solo se logra después de la II (segunda) guerra mundial, bajo la vigencia de la "Ley Fundamental de Bonn" de 1949. El decidido reconocimiento del individuo como titular de derechos fundamentales, conforme a la apreciación social, ha influido esencialmente en el proceso penal y paulatinamente ha llevado a una sensibilización frente a prácticas de persecución penal, que hace cien años no habrían tenido consecuencias legales. ${ }^{57}$

Resulta sorprendente, sin embargo, que también a esta doctrina de las prohibiciones probatorias, en especial por parte de la jurisprudencia, se le hayan introducido reservas. Estas debilitan la eficacia de esta doctrina, sobre todo en lo relativo a la grave criminalidad y siguen, de esa forma, una tendencia ya visible en el caso del derecho material. En el caso de las denominadas prohibiciones de prueba autónoma, ${ }^{58}$ la posibilidad de utilización de ciertos medios probatorios depende también del tipo de criminalidad de que se trate: así, de tratarse de medios de prueba que pertenecen a la esfera de la privacidad de las personas, su uso no estará permitido si de lo que se trata es la aclaración de hechos de menor relevancia (por ejemplo, daños materiales); mientras que, por el contrario, estos medios podrán ser utilizados -según la jurisprudencia- si de lo que se trata es de la aclaración de delitos de mayor gravedad. ${ }^{59}$ En el caso de las denominadas prohibiciones de prueba dependientes, donde de lo que se trata es de las

\footnotetext{
56 Esto queda claro, además, en la comparación del tratamiento de la temática en los distintos manuales, por ejemplo, el manual de GRAF ZU DOHNA (1929), pp. 90 y ss. se comenta el trabajo de BELINGS (1903) en la bibliografía; sin embargo, comentarios sustanciales para este problema se encuentran en pp. 90-114. No se encuentran, sin embargo, en cuanto a la doctrina de la prueba. Véase también HENKEL (1953), p. 259 y s. En cambio, la doctrina de las prohibiciones de prueba hoy en día es el tema más tratado del derecho procesal penal. Solamente se deben comparar las extensas bibliografías en un "manual corto" como el de ROXIN (1998), pp. 178 y ss., en el cual se dedican casi 20 páginas al tema.

${ }^{57}$ Este efecto de los derechos fundamentales y del cambio social es más visible en las prohibiciones de (utilización de) prueba autónoma basadas directamente en los derechos fundamentales; véase BGHSt 14, 358 y ss.; 19, 325 y ss.; 34, 397, 399 y ss.; BVerfGE 34, 238, 245 y ss., y una vista general en ROXIN (1998), \24 Nm. 41 - 46 con amplias referencias. Detalladamente en JäGER (2003), pp. 4 y ss., pp. 215 y ss.

58 En cuanto al término, Roxin (1998), \ 24 Nm. 23, 41 y ss.

${ }^{59}$ Cfr. BGHSt 36, 167, 173; Roxin (1998), \ 24 Nm. 44. con amplias referencias. Distinto es en el caso de los medios de prueba cuya utilización vulneraría el ámbito inviolable de la personalidad y con ello de la dignidad humana (BVerfGE 34, 238, 245).
} 
consecuencias de una deficiente obtención de prueba, la idea de la dependencia de su uso en relación con la importancia y el tipo de criminalidad ya no encuentra cabida de una manera así tan claramente acentuada. ${ }^{60}$ No obstante lo anterior, también aquí se abren distintas relativizaciones de la doctrina de prohibición probatoria - para casos de criminalidad más grave y peligrosa- de manera que se pueda prescindir del presupuesto de la prohibición de prueba respectiva. ${ }^{61}$

\section{Nuevas formas de dar "término" al procedimiento penal}

Finalmente, también se observan importantes cambios en la forma de dar término a las causas penales. La sentencia condenatoria, basada en la aclaración completa de los hechos en un juicio oral, ha sido relegada cada vez más a un plano secundario. En su lugar se producen crecientemente arreglos consensuados. Ellos se pueden llevar a la práctica por medio de los (simples) términos anticipados que son consecuencia del principio de oportunidad. ${ }^{62}$ Estas posibilidades se han ido ampliando progresivamente. Además de los términos simples se han introducido posibilidades de suspensión con sujeción a condiciones. ${ }^{63}$ Entretanto, el arreglo consensuado ya desde hace tiempo ha pasado a comprender también la forma de terminar los procedimientos por delitos graves. Si bien es cierto que, por regla general, se llega a una sentencia, ${ }^{64}$ sin embargo, esta ya no es necesariamente el resultado de un juicio oral, en que se ha agotado el estudio detallado de todas las pruebas y en que las circunstancias de hecho han sido aclaradas conforme a todos los escenarios posibles. Esta sentencia expresa comúnmente solo aquello que han convenido las partes en el juicio (normalmente con la renuncia de un posterior esclarecimiento de los hechos) en el transcurso de los llamados acuerdos procesales (Absprache). La Fiscalía y el tribunal prescinden normalmente de seguir aclarando el caso en todas sus direcciones y en sus diversos aspectos; el acusado se compromete a una confesión limitada y recibe a cambio la promesa de recibir una

\footnotetext{
${ }^{60}$ En este caso, se destaca - con punto de vista relevante de ponderación- más el peso del error, véase BGHSt 38, 214, 220 y 372, 373 y ss.

${ }^{61}$ Dignas de mención, aparte de la referencia al peso limitado del error, son las relativizaciones en la configuración de la accesibilidad de los medios de prueba, incluso en el caso de un proceder sin errores (relevancia del llamado sumario hipotético; BGH NStZ 1989, 375, 376; LG Darmstadt StV 1993, 573, 574 y ROGALL (1988), pp. 385 y ss. como también ROXIN (1998), \ 24 Nm. 21 y JÄGER (2003), pp. 117 y ss., pp. 229 y ss.) y la irrelevancia del error en lo referido a los fines de protección limitados de la prohibición de presentación de la prueba vulnerada (véase BGHSt 24, 125; de acuerdo SCHÜNEMANN (1972), p. 635; ROXIN (1998), \ 24 Nm. 37 con amplias referencias; detalladamente en JäGER (2003), pp. 82 y ss., pp. 128 y s., quien desarrolla una doctrina propia acerca del propósito de la protección).

62 Véase para esto $\iint 153$ y ss. StPO.

${ }^{63}$ Cfr. especialmente la importante disposición para la práctica del $\ 153$ a StPO.

${ }^{64}$ ¡Pero no siempre! Como prueba, que se ha hecho uso de la suspensión bajo condiciones incluso en casos de criminalidad mediana, causando un daño considerable, Cfr. EISENBERG (2005), \ 27 Nm. 68 y ss., en especial 79; MEYER-Gossner (2008), \ 153 a Nm. 1.
} 
sentencia referida solo a algunos puntos de acusación y no más allá de un determinado grado. ${ }^{65}$

Estas modificaciones (según algunos: deformaciones) ${ }^{66}$ del proceso y del derecho procesal, tampoco salen de la nada. Detrás de estas modificaciones en el derecho se presentan cambios sociales en sentido amplio. Y no se trata de un solo fenómeno. Varias circunstancias y modificaciones en el ámbito social concurren en este caso.

Un rol importante juegan en este caso, como también en el caso de los cambios en el derecho material, las profundas modificaciones producidas en las propias formas de criminalidad. A menudo se trata de situaciones complejas compuestas por una gran cantidad de hechos delictivos y de difícil análisis y entendimiento, y que frecuentemente presentan una vinculación internacional. Piénsese sobre todo en las causas en el ámbito penal económico, tributarias y en amplios ámbitos de la criminalidad organizada. ${ }^{67}$ Así, si lo que se quiere es concluir la causa de manera absoluta dentro de un periodo previsible, se debe hacer un esfuerzo de concentración. Se agregan dificultades en la demostración probatoria. Frente a esto, la oferta de una confesión limitada, a cambio de la renuncia a la verificación de otros aspectos, aparece frecuentemente como el único salvavidas para llegar, de alguna manera, a una sentencia condenatoria. Entonces, frente a una chance limitada de una completa aclaración y frente al riesgo de una sentencia fácilmente reversible, con una base cuestionable, se opta solo por una condena penal limitada bajo un acuerdo mutuo.

Por cierto, detrás de tales acuerdos no hay solamente nuevas dimensiones de criminalidad y dificultades para su aclaración. Cambios en el ámbito de la defensa juegan adicionalmente un rol que no debe ser subestimado. Algunos abogados defensores utilizan cada vez más el instrumental procesal, especialmente el derecho a solicitar pruebas, para que en forma de una defensa de conflictos, ${ }^{68}$ el tribunal se "desgaste" por medio de la presentación de siempre nuevas y difícilmente rechazables solicitudes de prueba (o conseguir una causal de anulación a través de rechazos errados). Algunos abogados defensores utilizan esta estrategia no solamente en juicios importantes, sino también en juicios de

\footnotetext{
65 Para los requisitos de la admisibilidad de tales acuerdos, fundamentalmente BGHSt 43, 195; 50, 40; vista general de la literatura controversial, en MEYER-GOSSNER (2008), Nm. 119 y ss., previo \ 213 Nm. 8 y ss. con amplias referencias. Los requisitos desarrollados por esta jurisprudencia para la admisibilidad de esos acuerdos se han incluido, en general, en la ley para la regulación del acuerdo en el proceso penal de 29 de junio de 2009 (BGBl. 2009 I p. 2353), véase especialmente \257c StPO.

${ }^{66}$ Especialmente insistente, en contra de la práctica de acuerdos en SCHÜNEMANN (1990), pp. 66 y ss.; SCHÜNEMANN (1992), pp. 361 y ss.; además SCHÜNEMANN (2005) y SCHÜNEMANN (2006).

${ }^{67}$ Sobre las dificultades de aclaración de casos de criminalidad organizada y la práctica de acuerdos en esos casos, véase KINZIG (2004), pp. 802 y ss.

68 Véase para detalles DAHS (2005), Nm. 36, 71, 198, 444, 695, 807; JAHN (1998), especialmente pp. 54 y ss.; además HAMM (2006), pp. 2084 y ss.
} 
criminalidad leve o mediana. Algunos juicios de este ámbito pueden prolongarse a causa de estas prácticas, sin problema, por varios meses. Es fácil comprender entonces que los tribunales, con una capacidad limitada de resolución y frente a tales estrategias, se conformen finalmente con aceptar un arreglo que, con una base modesta, logre alcanzar algún tipo de sentencia, que al menos tenga la posibilidad de permanecer en el tiempo.

Naturalmente no son suficientes los cambios producidos en el ámbito de la criminalidad ni en el comportamiento de determinados sujetos intervinientes del proceso penal como para explicar un cambio provocado en el procedimiento y en el derecho procesal. Estos respectivos cambios fácticos no desembocarían en una práctica distinta relativa al término de proceso penal, si paralelamente no estuvieran acompañados por transformadas concepciones acerca de los fines del proceso penal por parte también de los tribunales y del Ministerio Público. Aparentemente, para algunos, encontrar la sentencia más justa y la aclaración completa de los hechos ya no es necesariamente la finalidad fundamental del proceso. Parece mucho más importante terminar el juicio de una manera aceptable y lograrlo dentro de un período de tiempo razonable. Sin esta concepción sería difícil la cada vez más creciente práctica de los acuerdos. La justicia ha dejado de ser la meta fundamental. Por el contrario, parece ser más importante que algo suceda, de alguna forma que pueda ser considerada como aceptable. 
Frisch - Transformaciones del derecho penal como consecuencia del cambio social

\section{BIBLIOGRAFÍA}

* AlBrecht, Hans-Jörg (2003): “Tatproportionalität in der Strafzumessungspraxis", en Frisch e.o. (ed.), Tatproportionalität (Heidelberg, Ed. C.F.Müller), pp. 215-242.

(2006): “Antworten auf Gefährlichkeit - Sicherungsverwahrung und unbestimmter Freiheitsentzug”, en Feltes e.o. (ed.) Festschrift für Schwind (Wien, Ed. Manz), pp. 191-210.

* Albrecht, Peter-Alexis (2005): “"Krieg gegen den Terror' - Konsequenzen für ein rechtsstaatliches Strafrecht”, en Zeitschrift für die gesamte Strafrechtswissenschaft (N. 117), pp. 852- 864.

* Ambros, Dankmar (1965): “Artikel Gesellschaft", en Beckerath e.o. (coord.), Handwörterbuch der Sozialwissenschaften (Stuttgart, Ed. Fischer), tomo 4, pp. 427-433.

* Beling, Ernst von (1903): Beweisverbote als Grenze der Wabrheitserforschung (Frankfurt a.M., Ed. Keip), 40 pp.

* CANCiO Meliá, Manuel (2005): "Feind"strafrecht"?", en Zeitschrift für die gesamte Strafrechtswissenschaft (N. 117), pp. 267-289.

(2007): “Zum Unrecht der kriminellen Vereinigung: Gefahr und Bedeutung”, en Pawlik/Zaczyk (ed.) Festschrift für Jakobs (Ed. Heymanns), pp. 27-52.

* Cerezo Mir, José (2008): "Kritische Bemerkungen über die nachträgliche Sicherungsverwahrung und über die jüngste Entwicklung der Rechtsprechung des spanischen Höchsten Gerichtshofes über die Strafrechtsanwendung bei der Realkonkurrenz", en Sieber e.o. (ed.) Festschrift für Tiedemann (Köln, Ed. Heymanns), pp. 405- 412.

* DAHS, Hans (2005): Handbuch des Strafverteidigers (Köln, Ed. O. Schmidt), $7^{\mathrm{a}}$ ed., 776 pp.

* DitTrich, Joachim (1998): “Der 'Große Lauschangriff - diesseits und jenseits der Verfassung”, en Neue Zeitschrift für Strafrecht (N. 18), pp. 336-338.

* DutTge, Gunnar (2002): "Die Präimplantationsdiagnostik zwischen Skylla und Charybdis”, en Goltdammer's Archiv für Strafrecht (N. 149), pp. 241-258.

* Eisenberg, Ulrich (2005): Kriminologie (München, Ed. Beck), 6ª ed., 1185 pp.

* ErB, Völker (2008): “Kommentierung”, en Löwe/Rosenberg (ed.) Die Strafprozessordnung und das Gerichtsverfassungsgesetz (Berlin, Ed. De Gruyter), $26^{\mathrm{a}}$ ed., vor $\ 158$.

* Eser, Albin (2000): "Schlußbetrachtungen", en Eser e.o. (ed.) Die deutsche Strafrechtswissenschaft vor der Jahrtausendwende (München, Ed. Beck), pp. 437-448.

* ExNer, Franz (1931): Studien über die Strafzumessungspraxis der deutschen Gerichte (Leipzig, Ed. Wiegandt), $119 \mathrm{pp}$.

* FisCHER, Thomas (2008): Strafgesetzbuch und Nebengesetze (München, Ed. Beck), $55^{\mathrm{a}}$ ed., 2594 pp.

* Folkers, Susanne (2006): "Die nachträgliche Sicherungsverwahrung in der Rechtsanwendung - Eine Zwischenbilanz”, en Neue Zeitschrift für Strafrecht (N. 26), pp. 426-434.

* FreIER, Friedrich von (2008): "Verfahrensidentität und Prozessgegenstand des Verfahrens zur nachträglichen Anordnung der Sicherungsverwahrung”, en Zeitschrift für die gesamte Strafrechtswissenschaft (N. 120), pp. 273-330.

* Frisch, Wolfgang (1990): "Die Maßregeln der Besserung und Sicherung im strafrechtlichen Rechtsfolgensystem”, en Zeitschrift für die gesamte Strafrechtswissenschaft (N. 102), pp. 343-393.

(1993): Verwaltungsakzessorietät und Tatbestandsverständnis im Umweltstrafrecht

(Heidelberg, Ed. C.F. Müller), 156 pp.

(2000a): "Grundlinien und Kernprobleme des deutschen Umweltstrafrechts", en Leipold (ed.), Umweltschutr, und Recht in Deutschland und Japan (Heidelberg, Ed. C.F.Müller), pp. 361-401.

(2000b): "Strafkonzept, Strafzumessungstatsachen und Maßstäbe der Strafzumessung in der Rechtsprechung des BGH”, en Roxin/Widmaier (ed.) 50 Jahre Bundesgerichtshof. Festgabe aus der Wissenschaft (München, Ed. Beck), tomo IV, pp. 269-308.

(2002): "Sicherheit durch Strafrecht? Erwartungen, Möglichkeiten und Grenzen", en Duttge e.o. (ed.) Gedächtnisschrift für Ellen Schlüchter (Köln e.o., Ed. Heymanns), pp. 669-689. 
(2004): “Sicherungsverwahrung", en Ambs (ed.) Lexikon des Rechts (Neuwied, Ed. Luchterhand), tomo 8, $3^{\mathrm{a}}$ ed., pp. 1-13.

* Ganslandt, Herbert R. (2005): “Artikel: Gesellschaftsvertrag”, en Mittelstraß (coord.) Enzyklopädie Philosophie und Wissenschaftstheorie (Stuttgart, Ed. Metzler), tomo 1, pp. 756-761.

* Göppinger, Hans (2008): Kriminologie (München, Ed. Beck), 6a ed., 781 pp.

* Gössel, Karl-Heinz (2006): "Widerrede zum Feindstrafrecht - Über Menschen, Individuen und Rechtspersonen”, en Hoyer e.o. (ed.) Festschrift für Schroeder (Heidelberg, Ed. C.F.Müller), pp. 33-66.

* GÖTTING, Bert (1997): Gesetzlicher Strafrahmen und Strafzumessungspraxis (Frankfurt a.M., Ed. Peter Lang), 236 pp.

* Graf Zu Dohna, Alexander (1929): Strafprozeßrecht (Berlin, Ed. Heymanns), 3 a ed., 281 pp.

* Greco, Luis (2006): "Über das so genannte Feindstrafrecht", en Goltdammer's Archiv für Strafrecht (N. 153), pp. 96-113.

* Halder, Alois/MÜller, Max (2008): "Gesellschaft", en Philosophisches Wörterbuch (Freiburg i.B. e.o., Ed. Herder), pp. 122-123.

* Hamm, Rainer (2006): "Ist Strafverteidigung noch Kampf?", en Neue Juristische Wochenschrift (N. 59), pp. 2084-2089.

* Harendorf, Stefan (2008): "Wo sind die Adressaten der Sicherungsverwahrung? Zur Rückfallgefahr schwerer Gewalttäter", en Juristische Rundschau, pp. 6-16.

* Hassemer, Winfried (1989): "Symbolisches Strafrecht und Rechtsgüterschutz", en Neue Zeitschrift für Strafrecht (N. 9), pp. 553-559.

* Henkel, Heinrich (1953): Strafverfahrensrecht (Stuttgart/Köln, Ed. Kohlhammer), 514 pp.

* Hörnle, Tatiana (2006): "Deskriptive und normative Dimensionen des Begriffs 'Feindstrafrecht", en Goltdammer's Archiv für Strafrecht (N. 153), pp. 80-95.

* JägER, Christian (2003): Beweisverwertung und Beweisverwertungsverbote im Strafprozess (München, Ed. Beck), 305 pp.

* JAKOBS, Günther (1985): "Kriminalisierung im Vorfeld einer Rechtsgutsverletzung", Zeitschrift für die gesamte Strafrechtswissenschaft (N. 97), pp. 751-785.

(2005): "Terroristen als Personen im Recht?", en Zeitschrift für die gesamte Strafrechtswissenschaft (N. 117), pp. 839-851.

* JAHN, Matthias (1998): Konfliketverteidigung und Inquisitionsmaxime (Baden-Baden, Ed. Nomos), 387 pp.

* KaISER, Günther (1996): Kriminologie (Heidelberg, Ed. C.F.Müller), $3^{\text {a }}$ ed., 1256 pp. (1979): “Was wissen wir von Strafe?”, en Arthur Kaufmann e.o. (ed.), Festschrift für Bockelmann (München, Ed. Beck), pp. 923- 642.

* Kaupp, Peter (1974): “Artikel Gesellschaft”, en: Bien e.o. (coord.) Historisches Wörterbuch der Philosophie (Basel, Ed. Schwabe), tomo 3, pp. 459-466.

* Kempf, Eduard (1997): "Die Funktion von Strafrecht und Strafverteidigung in einer modernen Gesellschaft", en Neue Juristische Wochenschrift (N. 50), pp. 1729-1736.

* KInZIG, Jörg (1996): Die Sicherungsverwahrung auf dem Prüfstand (Freiburg i.B., Ed. Iuscrim MPI), 694 pp.

(2004): Die rechtliche Bewältigung von Erscheinungsformen organisierter Kriminalität (Berlin, Ed. Duncker \& Humblot), 849 pp.

* Krey, Volker /HAUBRICH, Edgar (1992): “Zeugenschutz, Rasterfahndung, Lauschangriff, Verdeckte Ermittler”, en Juristische Rundschau, pp. 309- 315.

* KüHL, Kristian (1987): "Probleme der Verwaltungsakzessorietät des Strafrecht, insbesondere im Umweltstrafrecht", en Puppe/Tenckhoff (ed.), Festschrift für Lackner (Berlin, Ed. de Gruyter), pp. 815- 861.

* KuHLen, Lothar (2000): "Strafrechtliche Produkthaftung”, en Roxin/Widmaier (ed.) 50 Jabre Bundesgerichtshof. Festgabe aus der Wissenschaft (München, Ed. Beck), tomo IV, pp. 647-673.

* LANGE, Nicole (1999): Vorermittlungen (Frankfurt a.M., Ed. Peter Lang), 256 pp. 
Frisch - Transformaciones del derecho penal como consecuencia del cambio social

* Lappi-Seppälä, Tapio (2003): "Das Proportionalitätsprinzip in der finnischen Strafzumessungspraxis”, en Frisch e.o. (ed.), Tatproportionalität (Heidelberg, Ed. C.F.Müller), pp. 261-288.

* Laubenthal, Klaus (2004): "Die Renaissance der Sicherungsverwahrung”, Zeitschrift für die gesamte Strafrechtswissenschaft (N. 116), pp. 703-750.

* Leutheusser-Schnarrenberger, Sabine (1998): "Der 'große Lauschangriff Sicherheit statt Freiheit”, en Zeitschrift für Recht und Politik (N. 31), pp. 87-91.

* Lilie, Hans (2007): "Neue Probleme des Embryonenschutzgesetzes", Hettinger e.o. (ed.), Festschrift für Küper (Heidelberg, Ed. Müller), pp. 305-312.

* LiszT, Franz von (1905): "Kriminalpolitische Aufgaben”, en Strafrechtliche Aufsätze und Vorträge (Berlin, Ed. Guttentag), tomo I 1875/1891, 560 pp.

* LöffelmanN, Markus (2005): "Die Neuregelung der akustischen Wohnraumüberwachung", en Neue Juristische Wochenschrift (N. 58), pp. 2033-2036.

* Maurer, Matthias (2005): Komparative Strafzumessung (Berlin, Ed. Duncker \& Humblot), 244 pp.

* Meertens, Christoph (1992): "Das Gesetz gegen Organisierte Kriminalität, eine unerträgliche Geschichte!”, en Zeitschrift für Recht und Politik (N. 25), pp. 205-208.

* Meyer-Gossner, Lutz (2008): Strafprozessordnung-Kommentar (München, Ed. Beck), $51^{\mathrm{a}}$ ed., 2192 pp.

* Milde, Oliver (2006): Die Entwicklung der Normen zur Anordnung der Sicherungsverwabrung von 1998 bis 2004 (Hamburg, Ed. Kovač), 389 pp.

* Müller, Christian (1997): Das Gewohnheitsverbrechergesetz vom 24. November 1933 (BadenBaden, Ed. Nomos), 120 pp.

* Paeffgen, Hans-Ulrich (1995): "Verpolizeilichung” des Strafprozesses - Chimäre oder Gefahr?, en Wolter (ed.) Theorie und Systematik des Strafprozeßrechts (Neuwied, Ed. Luchterhand), pp. 13-47. (2003): "Vernachrichtendienstlichung des Strafprozesses" en Goltdammer's Archiv für Strafrecht (N. 150), pp. 647-671.

* Pérez Del VALLe, Carlos (2007): “Zur rechtsphilosophischen Begründung des Feindstrafrechts”, en Pawlik/Zaczyk (ed.) Festschrift für Jakobs (Ed. Heymanns), pp. 515-528.

* Polaino Navarrete, Miguel (2007): “Die Funktion der Strafe beim Feindstrafrecht", en Pawlik/Zaczyk (ed.) Festschrift für Jakobs (Ed. Heymanns), pp. 529-552.

* Puppe, Ingeborg (2000): “Urkundenschutz im Computerzeitalter", en Roxin/Widmaier (ed.) 50 Jahre Bundesgerichtshof. Festgabe aus der Wissenschaft (München, Ed. Beck), tomo IV, pp. 569-591.

* Rehbinder, Manfred (2007): Rechtssoziologie (München, Ed. Beck), 6a ed., 203 pp.

* Renzikowski, Joachim (2001): "Die strafrechtliche Beurteilung der Präimplantationsdiagnostik", en Neue Juristische Wochenschrift (N. 54), pp. 2753-2758.

* Rogall, Klaus (1988): "Hypothetische Ermittlungsverläufe im Strafprozeß. Ein Beitrag zur Lehre der Beweiserhebungs- und Beweisverwertungsverbote", en Neue Zeitschrift für Strafrecht (N. 8), pp. 385-392.

* Roxin, Claus (1998): Strafverfahrensrecht (München, Ed. Beck), 25 ed., 568 pp.

* SAliger, Frank (2006): "Feindstrafrecht: Kritisches oder totalitäres Strafrechtskonzept", en Juristische Zeitung (N. 61), pp. 756-762.

* SCHMIDT, Eberhard (1965): Einführung in die Geschichte der deutschen Strafrechtspflege (Göttingen, Ed. Vandenhoeck und Ruprecht), $3^{\mathrm{a}}$ ed., 481 pp.

* SCHÖCH, Heinz (1973): Strafzumessungspraxis und Verkebrsdelinquenz. (Stuttgart, Ed. Enke), 239 pp.

(2000): en Roxin/Widmaier (ed.) 50 Jahre Bundesgerichtshof. Festgabe aus der Wissenschaft (München, Ed. Beck). 
- SCHREIBER, Hans-Ludwig (2001): "Recht als Grenze der Gentechnologie", en Schünemann e.o. (ed.) Festschrift für Roxin (Berlin/New York, Ed. Walter de Gruyter), pp. 891- 904.

* SCHROTH, Ulrich (2002): "Forschung mit embryonalen Stammzellen und Präimplantationsdiagnostik im Lichte des Rechts”, en Juristische Zeitung (N. 57), pp. 170-179.

* Schulz, Stefan (2003): "Klonen an den Grenzen strafrechtlicher Wissenschaftsordnung", en Zeitschrift für Recht und Politik (N. 36), pp. 362-366.

* SchünemanN, Bernd (1972): "Der Besondere Beitrag - Rundum betrachtet", en Juristische Arbeitsblätter (N. 4), pp. 633- 640. (1990): Gutachten B zum 58. Deutschen Juristen Tagung, 178 pp.

_ (1992): "Die informellen Absprachen als Überlebenskrise des Strafverfahrens", en Festschrift für Baumann (Bielefeld, Ed. Gieseking), pp. 361- 382.

_ (2005): Strafprozessuale Absprachen in Deutschland (Regensburg, Ed. Roderer), 17 pp.

(2006): Wetterzeichen vom Untergang der deutschen Rechtskultur (Berlin, Ed. BWV Berliner Wissenschafts-Verlag), 38 pp.

* STEHLE, Susanne (2006) Das Strafverfahren als materielle Wiedergutmachung. Die aktiven Beteiligungsrechte des Verletzten im Verfahren vor dem Internationalen Strafgerichtshof und in ausgewählten nationalen Strafverfahren (Diss. Freiburg).

* Stoiber, Edmund (2006): “Zur Renaissance der Sicherungsverwahrung", en Hoyer e.o. (ed.) Festschrift für Schroeder (Heidelberg, Ed. C.F.Müller), pp. 3-10.

* Strate, Gerhard (1992): "Stellungnahme des Strafrechtsausschusses des Deutschen Anwaltsvereins (DAV) zum 'Entwurf eines Gesetzes zur Bekämpfung des illegalen Rauschgifthandels und anderer Erscheinungsformen der Organisierten Kriminalität (OrgKG)", en Strafverteidiger (N. 12), pp. 29-37.

* Walther, Susanne (2000): Vom Rechtsbruch zum Realkonfliket (Berlin, Ed. Duncker \& Humblot), 460 pp.

* Wesslau, Edda (1989): Vorfeldermittlungen (Berlin, Ed. Duncker \& Humblot), 364 pp.

\section{LEGISLACIÓN}

* "Entwurf eines Gesetzes zur Bekämpfung der Umweltkriminalität" (proyecto de ley para el combate de la criminalidad medioambiental), $18^{\mathrm{a}}$ ley de modificación del Derecho penal, consideraciones generales, N. 4, impreso de las sesiones del Parlamento Federal alemán, (Bundestag-Drucksachen) 8/2382.

* "Gesetz zum Schutz von Embryonen" (ley de protección a los embriones), de 13.12.1990 y de 23.10.2001, Publicación oficial de leyes federales (Bundesgesetzblatt: BGBl.) 2001.

* "Stammzellgesetz" (ley de células madre), de 28.6.2002, Publicación oficial de leyes federales (BGBl.) tomo I 2002 y (BGBl.) tomo I 2003.

* $12^{a}$ Ley de modificación del Derecho penal, de 1971.

* Ley contra la criminalidad organizada (OrgKG), impreso de las sesiones del Parlamento Federal alemán (BT-Drucks.), 12/989.

* Ley de la lucha contra la criminalidad, Publicación oficial de leyes federales (BGBl.), tomo I 1992.

* Ley de indemnización para víctimas de delitos violentos, de 7.1.1985, Publicación oficial de leyes federales (BGB1.), tomo I 1985.

* Ley para la regulación del acuerdo en el proceso penal, de 29.06.2009, Publicación oficial de leyes federales, (BGB1.) tomo I 2009.

\section{JURISPRUDENCIA}

* Tribunal Supremo Federal alemán (Bundesgerichtshof), asuntos penales (Strafsachen), 30.11.1953, Köln e.o. (Ed. Heymanns), t. 5, pp. 291-294. 
Frisch - Transformaciones del derecho penal como consecuencia del cambio social

* Tribunal Supremo Federal alemán, 14.06.1960, Köln t. 14, pp. 358-366.

* Tribunal Supremo Federal alemán, 21.02.1964, Köln t. 19, pp. 325-334.

* Tribunal Supremo Federal alemán, 17.03.1971, Köln t. 24, pp. 125-132.

* Tribunal Supremo Federal alemán, 11.05.1971, Köln t. 24, pp. 140-142.

* Tribunal Supremo Federal alemán, 09.07.1987, Köln t. 34, pp. 397-401.

* Tribunal Supremo Federal alemán, 12.04.1989, Köln t. 36, pp. 167-175.

* Tribunal Supremo Federal alemán, 6.02.1990, Köln t. 36, pp. 374-378.

* Tribunal Supremo Federal alemán, 27.02.1992, Köln t. 38, pp. 214-231.

* Tribunal Supremo Federal alemán, 28.08.1997, Köln t. 43, pp. 195-212.

* Tribunal Supremo Federal alemán, 03.03.2005, Köln t. 50, pp. 40-64.

* Tribunal Supremo Federal alemán, 15.02.1989, Neue Zeitschrift für Strafrecht 1989 (N. 8), pp. 375-379.

* Tribunal Superior del Estado de Bavaria (BayObLG), 11.05.1992, Nene Juristische Wochenschrift 1992, pp. 3311-3312.

* Tribunal Superior de Colonia (OLG Köln), 10.08.2001, Neue Juristische Wochenschrift 2002, pp. 527-528.

* Tribunal estadual de Darmstadt (LG), 12.08.1993, Strafverteidiger 1993, pp. 573-574.

* Tribunal Constitucional Federal alemán (Bundesverfassungsgericht), fallos, 31.01.1973, t. 34, pp. 238- 251.

* Tribunal Constitucional Federal alemán, 03.03.2004, t. 109, pp. 279-391. 